\title{
Infância, trabalho e saúde: reflexões sobre o discurso oficial de proibição do trabalho infantil
}

\author{
Childhood, work and health: reflections on the official discourse of \\ prohibition of child labor
}

Valdinei Santos de Aguiar Junior', Luiz Carlos Fadel de Vasconcellos²

RESUMO Este texto apresenta alguns resultados e hipóteses levantados em pesquisa sobre a relação entre infância, trabalho e saúde que analisou o processo histórico de construção do discurso oficial (leis e políticas) da proibição do trabalho infantil, utilizando os procedimentos da Análise de Discurso. Verificou-se a presença de elementos indicativos de funcionamento ideológico que sustentam a 'invisibilidade do trabalho infantil' e 'demarcação do trabalho enquanto atividade inerentemente prejudicial à saúde’. Aponta para a necessidade de estudos e pesquisas que considerem a complexidade da temática do trabalho infantil e suas relações com a saúde pública.

PALAVRAS-CHAVE Saúde infantil. Trabalho. Saúde pública. Saúde do trabalhador. Trabalho infantil.

ABSTRACT This paper presents some results and hypotheses obtained from research on the relationship between childhood, work and health which analyzed the historical process of building the official discourse (laws and policies) of prohibition of child labor, using the procedures of Speech Analysis. The presence of indicative elements of ideological operation was found to support the 'invisibility of child labor' and 'demarcation of work as an inherently harmful activity to health'. It points to the need for studies and research to consider the complexity of the child labor issue and its relationship with public health.

1 Fundação Oswaldo Cruz

(Fiocruz), Escola Nacional de Saúde Pública Sergio

Arouca (Ensp) - Rio de

Janeiro (RJ), Brasil

vival_rj@hotmail.com

2 Fundação Oswaldo Cruz (Fiocruz), Escola

Nacional de Saúde

Pública Sergio Arouca

(Ensp). Departamento de

Direitos Humanos, Saúde

e Diversidade Cultural

(DIHS) - Rio de Janeiro

(RJ), Brasil.

elfadel@globo.com

KEYWORDS Child health. Work. Public health. Occupational health. Child labor. 
Eu não queria ocupar o meu tempo usando palavras bichadas de costumes. Eu queria mesmo desver o mundo. Menino do Mato - Manoel de Barros

\section{Introdução}

A infância, enquanto coletividade e categoria estrutural da sociedade, e o trabalho, como uma atividade social e central na determinação das condições de saúde e vida das populações, podem ter suas correlações analisadas em diversas questões a serem consideradas na produção de conhecimentos e de políticas de saúde. Entretanto, abordar a relação entre infância e trabalho remete, mais comumente, às questões referentes ao que se denomina 'trabalho infantil', compreendido como toda forma de trabalho exercido por pessoa abaixo da idade mínima permitida em lei para tal trabalho. Desde as primeiras leis trabalhistas da Revolução Industrial inglesa, até aos principais documentos normativos internacionais sobre o trabalho no mundo, o estabelecimento de idades mínimas para o trabalho se apresentou como uma regra primordial e uma questão (problema) fundamental para a construção de um direito do trabalho, sobretudo, no que tange ao direito à saúde no trabalho.

Com a Convenção $\mathrm{n}^{0}$ 138, publicada em 1973, e a Convenção ${ }^{\circ} 188$ de 1999, da Organização Internacional do Trabalho (OIT), os Estados signatários se comprometeram em eliminar o trabalho infantil do mundo, especialmente em suas piores formas. Contudo, a exploração do trabalho infantil é um problema social que, apesar das reduções nos números de crianças em situação de trabalho, ainda está longe de ser erradicado. A OIT apontou, no ano de 2013, uma redução ocorrida nos últimos anos, estimando ter caído para 168 milhões o número de crianças trabalhando ao redor do mundo, sendo que, destas, 86 milhões se encontram naquelas consideradas as "piores formas de trabalho infantil” (OIT, 2013A).
No ano de 2013, o Brasil foi reconhecido como um dos países que mais avançaram na redução do trabalho infantil. Todavia, voltou a apresentar um aumento no número de crianças em situação de trabalho no ano seguinte. Segundo a Pesquisa Nacional por Amostra de Domicílios (PNAD) de 2014, houve um aumento em relação ao ano de 2013 de 9,3\% de crianças entre 5 e 13 anos trabalhando no País, passando de 506 mil para 554 mil crianças nessa faixa etária trabalhando. Esse aumento, bem como o elevado número de crianças ainda em situação de trabalho no mundo, põe em dúvidas a viabilidade de objetivos pactuados internacionalmente como: erradicar o trabalho infantil em suas piores formas até 2016 (OIT, 2013B), e de "até 2025 acabar com o trabalho infantil em todas as suas formas" (ONU, 2015).

No Brasil, o Decreto $\mathrm{n}^{\circ}$ 6.841, publicado em 12 de junho de 2008, aprova e regulamenta a Lista das Piores Formas de Trabalho Infantil (Lista TIP) especificando uma lista com 89 itens de "Trabalhos Prejudiciais à Saúde e à Segurança" que traz em cada item a "Descrição do Trabalho", os "Prováveis Riscos Ocupacionais" e os "Prováveis Riscos à Saúde" (BRASIL, 2008). Entretanto, apesar de agravos à saúde serem o principal argumento utilizado para a classificação e proibição dos tipos de trabalho considerados piores formas, a temática ainda não recebe a devida atenção de sociedade, governos e Estado enquanto um problema também de saúde pública, sendo abordado prioritariamente como uma pauta da pasta de Trabalho e Emprego e/ou pelos setores que garantem, promovem e defendem os direitos de crianças e adolescentes.

A questão do trabalho infantil, contudo, correlaciona-se diretamente com a situação de saúde de crianças e adolescentes, bem como com a atenção à saúde das populações, especialmente no que tange ao campo da saúde do trabalhador. A Portaria $\mathrm{n}^{\circ} 777$ define que $o$ acidente de trabalho com crianças e adolescentes é um agravo à saúde do trabalhador de notificação compulsória (BRASIL, 
2004), e a Portaria $\mathrm{n}^{0} 1.832$, que estabelece a Política Nacional de Saúde do Trabalhador e da Trabalhadora, define que é uma ação de saúde do trabalhador na atenção primária em saúde incluir a situação das "crianças e adolescentes trabalhando" como uma das "prioridades de maior vulnerabilidade em saúde do trabalhador" (BRASIL, 2012). Diante do alto número de crianças e adolescentes que trabalham, sendo em grande parte em atividades proibidas, a atenção à saúde dessa parcela da população em sua relação com o trabalho se apresenta como um desafio para as políticas e ações em saúde. Ademais, o tema do trabalho infantil traz questões que, analisadas criticamente, são fundamentais para pensar em uma perspectiva ampliada que compreenda a dimensão social do trabalho na determinação das condições de saúde das populações.

Ao considerar a complexidade da temática e a dificuldade de eliminação da exploração do trabalho infantil no Brasil e no mundo, o presente texto apresenta uma análise crítica do processo histórico de construção do discurso oficial da proibição jurídica e combate ao trabalho infantil. Dessa forma, visa trazer elementos e considerações que possam acrescentar perspectivas e ampliar o enfrentamento do problema da exploração do trabalho de crianças e adolescentes, assim como contribuir com reflexões acerca da saúde do trabalhador, na perspectiva das relações saúde/trabalho. Para tanto, foi realizada pesquisa dos principais documentos normativos referentes à relação entre infância e trabalho e à proibição do trabalho infantil que, após organizados e sistematizados, foram analisados utilizando estratégia e fundamentação da Análise de Discurso (AD) (ORLANDI, 2000, 1983).

\section{Material e métodos}

Este trabalho se refere à apresentação de alguns achados e hipóteses resultantes de pesquisa sobre a construção sócio-histórica do discurso da proibição jurídica do trabalho infantil. Foram feitos levantamento e análise de documentos oficiais que correlacionassem os temas 'infância' e 'trabalho'. Após constituído um corpus de análise por meio da sistematização dos documentos a serem analisados, a estratégia de leitura, análise e compreensão dos documentos foi fundamentada na AD (ORLANDI, 1983, 2000).

$\mathrm{A} A D$, que se fundamenta em pressupostos de três campos de saber (linguística, marxismo e psicanálise), busca compreender como, por meio da linguagem, ideologia e inconsciente produzem sentidos no discurso, tendo em vista que, mediante o discurso, as práticas políticas exercem sua ação sobre as relações sociais (ORLANDI, 1983, 2000; ROCHA; DEUSDARÁ, 2006). "As palavras refletem sentidos de discursos já realizados, imaginados ou possíveis e desse modo a história se faz presente na língua", e a ideologia tem como função "produzir evidências, colocando o homem na relação imaginária com suas condições materiais de existência”, ou seja, torna possível a relação palavra/coisa - que não é natural, nem é reflexo de uma evidência - e sustenta a impressão de que uma determinada coisa ou fenômeno só pode ser dito de uma forma, e não de outras (ORLANDI, 2000, P. 67). Dessa forma, buscou-se compreender, por meio da análise dos documentos selecionados, os efeitos de sentido produzidos no e pelo discurso oficial a respeito da relação infância e trabalho considerando que tais discursos e efeitos de sentido são construções sócio-históricas.

Para Foucault (1996, P. 10),

o discurso não é simplesmente aquilo que traduz as lutas ou os sistemas de dominação, mas aquilo por que, pelo que se luta, o poder do qual queremos nos apoderar.

Na estratégia de análise, verificou-se que os enunciados sobre o trabalho e a infância, sobretudo no processo histórico que define o 'trabalho infantil' enquanto o problema social a ser enfrentado, também estiveram 
sujeitos a lutas e conflitos de interesses. Orlandi (2000, P. 60) demonstra que

[...] uma mesma palavra, na mesma língua, significa diferentemente, dependendo da posição do sujeito e da inscrição do que diz em uma ou outra formação discursiva.

Assim, uma questão que norteou a análise foi como ou por que o termo 'trabalho infantil' começou a ser mais comumente denominado como o problema social, e não outros termos como, por exemplo, 'exploração do trabalho infantil' ou o 'emprego ilegal de crianças e adolescentes'. A AD busca pensar o sentido - das palavras, dos textos, do discurso - dimensionado no tempo e no espaço das práticas do homem (ORLANDI, 1983). Em suma, a análise considerou as mudanças e as repetições de efeitos de sentidos, os conflitos de interesses, os contextos dos discursos desde as primeiras leis que regularam a participação de crianças no trabalho industrial até as atuais leis que visam erradicar o trabalho infantil do mundo. Assim, buscou compreender como, por intermédio e no discurso, efeitos de sentido sobre a infância e o trabalho foram e são produzidos.

Para a composição do corpus de análise, dividiram-se a busca e organização dos documentos em duas partes (momentos históricos) para ampliar a perspectiva do processo da intervenção estatal sobre a infância e o trabalho. Para a primeira parte, foram selecionadas leis publicadas no Reino Unido no século XIX, por serem consideradas tanto um marco legal inaugural do direito trabalhista atual quanto por terem como questão central de suas normativas a participação de crianças e adolescentes no trabalho industrial (quadro1). Para a segunda parte, selecionaram-se os documentos (Convenções) da OIT - publicados desde sua fundação em 1919 até a atualidade e que abordassem a questão da infância -, por definirem diretrizes e conceitos assumidos pelos estados signatários, e leis brasileiras que abordassem a relação entre infância e trabalho (quadro 2).

Após a sistematização dos documentos, iniciou-se o procedimento analítico que, em $\mathrm{AD}$, volta-se para a via pela qual a formação ideológica se inscreve no processo discursivo e como este, então, textualiza-se. Dessa maneira, tendo em vista as 'condições de produção' do discurso - compreendido pelos sujeitos, situações e memória e que em um sentido estrito referem-se às circunstâncias de enunciação (contexto imediato) e em um sentido amplo à história (o contexto sócio-histórico, ideológico) -, buscou-se compreender efeitos de sentido produzidos por meio do discurso textualizado nos documentos e levantar hipóteses sobre como esses discursos podem produzir práticas e relações sociais.

Quadro 1. Lista de documentos selecionados e analisados: leis do Reino Unido, publicadas no século XIX, que trataram do trabalho de crianças e/ou da proteção de crianças

\begin{tabular}{ll}
\hline Ano & Documento \\
\hline 1802 & Health and Moral of Apprentices Act \\
1819 & Factory Act \\
1833 & Factory Act \\
1834 & Chimney Sweepers Act \\
1840 & Chimney Sweepers Act \\
1842 & Mines and Colleries Act \\
1844 & Factory Act \\
\hline
\end{tabular}


Quadro 1. (cont.)

\begin{tabular}{ll}
\hline 1847 & Factory Act \\
1850 & Factory Act \\
1864 & Chimney Sweepers Act \\
1867 & Factory Act \\
1875 & Chimney Sweepers Act \\
1875 & Intestates Wisdow and Child \\
1876 & Elementary Education Act \\
1878 & Factory Act \\
1879 & Children's Dangerous Act \\
1887 & Coal Mines Regulation Act \\
1889 & Prevention to Cruelty, and Better Protection of, Children Act \\
\hline
\end{tabular}

Quadro 2. Convenções da OIT e alguns documentos oficiais publicados no Brasil que abordam a relação infância/trabalho

\begin{tabular}{|c|c|c|}
\hline Ano & Documento & Autoria \\
\hline 1871 & Lei imperial no 2.040 (Lei do Ventre Livre) & BRASIL \\
\hline 1890 & Decreto no 439 (Assistência à infância desvalida) & BRASIL \\
\hline 1891 & Decreto no 1.313 (Regulariza o trabalho de menores nas fábricas...) & BRASIL \\
\hline 1919 & Convenção no 5 (Idade Mínima nas Indústrias) & OIT \\
\hline 1919 & Convenção no 6 (Trabalho noturno de Menores [indústria]) & OIT \\
\hline 1920 & Convenção no 7 (Trabalho Menores - Marítimo) & OIT \\
\hline 1921 & Convenção no 21 (Exame médico de menores no trabalho marítimo) & OIT \\
\hline 1923 & Decreto no 16.272 (Assistência e proteção aos menores abandonados...) & BRASIL \\
\hline 1926 & Decreto no 5.083 (Código de Menores) & BRASIL \\
\hline 1943 & Decreto-lei no 5.452 (Consolidação das Leis Trabalhistas) & BRASIL \\
\hline 1952 & Convenção no 103 (Amparo à Maternidade - revista) & OIT \\
\hline 1958 & Convenção no 58 (Idade mínima no trabalho marítimo - revista) 1958 & OIT \\
\hline 1965 & Convenção no 124 (Exame médico dos adolescentes para o trabalho subterrâneo) 1965 & OIT \\
\hline 1967 & Decreto no 5.274 (Dispõe sobre o salário mínimo de menores) & BRASIL \\
\hline 1973 & Convenção no 138 (Idade mínima de admissão ao emprego) 1973 & OIT \\
\hline 1981 & Convenção nº 155 (Segurança e Saúde dos Trabalhadores) 1981 & OIT \\
\hline 1985 & Convenção no 161 (Serviços de Saúde no Trabalho) 1985 & OIT \\
\hline 1988 & Constituição Federal do Brasil 1988 & BRASIL \\
\hline 1990 & Lei no 8.069 - Estatuto da Criança e do Adolescente (ECA) 1990 & BRASIL \\
\hline 1996 & Lei no 9.394 - Lei de Diretrizes e Bases da Educação 1996 & BRASIL \\
\hline 1999 & $\begin{array}{l}\text { Convenção no } 182 \text { - Proibição das Piores Formas de Trabalho Infantil e Ação Imediata para } \\
\text { sua Eliminação } 1999\end{array}$ & OIT \\
\hline 1999 & Decreto no 178 e Decreto no 179 & BRASIL \\
\hline
\end{tabular}




\begin{tabular}{lll}
\hline Quadro 2. (cont.) & \\
\hline 2000 & Lei no 10.097 (altera a CLT) 2000 & BRASIL \\
2004 & Cartilha do Programa de Erradicação do Trabalho Infantil (Peti) & BRASIL \\
2004 & Portaria no 777/2004 & BRASIL \\
2008 & Decreto no 6.481 (Lista TIP) Piores Formas 2008 & BRASIL \\
2013 & Carta de Brasília 2013 & OIT/BRASIL \\
\hline
\end{tabular}

\section{Resultados}

A forma como se constituiu o corpus de análises desta pesquisa possibilitou que a busca e a inclusão dos documentos expandissem a análise por, ao evidenciar a historicidade dos conceitos e do discurso, trazer alguns elementos para reflexão do processo histórico de proibição jurídica do trabalho infantil. Segundo Deakin e Simon (2005, P. 3), os conceitos legais são formulações e categorias abstratas que compõem a estrutura do discurso legal, provendo, portanto, um "quadro epistemológico de referência, um 'mapa cognitivo' das relações sociais e econômicas”. O estudo da construção do discurso oficial sobre o trabalho infantil, das condições de produção dos discursos textualizados nos documentos analisados, das mudanças e continuidades dos efeitos de sentido produzidos pelos conceitos jurídicos trouxeram elementos (constatações e hipóteses) que possibilitam reflexões acerca das relações sociais e econômicas referentes à relação entre infância e trabalho, especialmente no que tange ao trabalho de crianças.

$\mathrm{Na}$ presente análise, evidenciou-se que, com o advento e consolidação do modo de produção industrial capitalista, a necessidade de intervenção estatal sobre as relações de trabalho, sobretudo no trabalho industrial, e sobre a vida das crianças estiveram intimamente correlacionadas em suas gêneses. Em suma, a presença de crianças nas indústrias têxteis inglesas foi um fator crucial tanto para a necessidade de impor limites à exploração da força de trabalho suscitando um rol de leis trabalhistas quanto para a constatação de que as crianças na sociedade industrializada precisariam receber proteção, atenção e cuidados especiais. No que tange à saúde no trabalho, a sistematização das leis e documentos oficias selecionados demonstram um processo gradual no qual: primeiro se tentou estabelecer regras que protegessem a saúde das crianças que trabalhavam nas indústrias; depois se foi estabelecendo idades mínimas para o emprego e regras protetivas específicas de acordo com as idades dos trabalhadores. Paralelamente à regulação do trabalho de crianças e imposição de limites etários para o emprego, foram se estabelecendo a necessidade e a obrigatoriedade da escolarização das crianças.

Na totalidade do corpus, verificou-se 'saúde' e 'educação' (seja moral ou escolar) como os dois principais motivos que fundamentaram as intervenções do poder público relacionadas com o trabalho de crianças. Ou seja, proteger a saúde das crianças e garantir-lhes o direito à educação foram pautas norteadoras dos documentos selecionados para o corpus e fundamento do atual discurso de erradicação do trabalho infantil. Entretanto, se o mecanismo ideológico do discurso presente nos textos atuais sustenta a ilusão de que o combate ao trabalho infantil se volta prioritariamente para garantir os direitos individuais à saúde e à educação das crianças e adolescentes, assim o faz operando o 'esquecimento' de alguns pontos fundamentais - como o fato de que a construção destes direitos (à saúde e à escolarização) esteve intimamente relacionada com as demandas da 
própria organização econômica e que algumas significativas inversões de atribuições e sentidos foram ocorrendo na legislação dos últimos dois séculos. Por exemplo, o trabalho, anteriormente tido (no próprio discurso oficial) como valor e ferramenta de socialização das crianças, passou a representar uma violação dos direitos da infância, fazendo com que esta precisasse vir a ser protegida dos prejuízos causados pelo trabalho.

Para analisar se e como a ideologia presente no atual discurso, e constituinte deste, poderia estar operando esquecimentos sobre a história e as funções sociais tanto do trabalho de crianças e adolescentes quanto da própria construção desse discurso; levou-se em conta a multiplicidade de vozes, atores e interesses distintos que, na luta pelo poder do discurso, estiveram e se fazem presentes na consolidação do discurso oficial e, consequentemente, das práticas políticas referentes à relação entre infância e trabalho. Observou-se que, a despeito do necessário e evidente objetivo de proteger as crianças e adolescentes dos prejuízos causados pela inserção precoce no trabalho, outros aspectos fundamentais influenciaram e são influenciados pelo processo de construção jurídico-política de proibição do trabalho infantil. É interessante notar, por exemplo, por que, sendo esta uma pauta tão crucial no estabelecimento de regras jurídicas trabalhistas e sendo a exploração do trabalho de crianças uma prática utilizada no advento e consolidação do modo de produção industrial, somente em 1973 que a OIT especificou

[...] 'ter chegado o momento' de adotar um instrumento geral sobre a matéria, que substitua gradualmente os atuais instrumentos, aplicáveis a limitados setores econômicos, com vistas à total abolição do trabalho infantil. (OIT, 1973, GRIFO NOSSO).

Verifica-se materializado na língua, textualizado no próprio discurso da proibição, que a construção de regras jurídicas, bem como dos sentidos sociais sobre o trabalho de crianças é intimamente relacionado com as demandas socioeconômicas dos momentos históricos. Isto corrobora a impressão de que somente quando o trabalho das crianças pôde ser, de certa forma, prescindível ao modo de produção industrial capitalista, que então passou a ser proibido. Evidentemente que as bases da proibição se sustentam no objetivo de proteger as crianças e adolescentes, entretanto destaca-se que tal produção de efeitos de sentidos sobre o trabalho de crianças se vincula intimamente às demandas e necessidades do sistema econômico internacional.

Dentre as constatações da análise, vale destacar que, a primeira das leis das fábricas, a Health and Moral of Apprentices Act, de 1802, considerada um marco jurídico no que se refere aos moldes de contrato de trabalho, não visou estabelecer idades mínimas ou acabar com o trabalho dos aprendizes (crianças e adolescentes) nas indústrias têxteis; mas sim em estabelecer regras e condições de trabalho visando proteger a saúde e a moral destes trabalhadores. Em suma, sobre essa lei que se aplicava especialmente às indústrias têxteis que utilizavam o trabalho de aprendizes, destacam-se quatro aspectos verificados com a análise da formação discursiva desse documento e de suas condições de produção do discurso: a) esta primeira intervenção do Estado não visou proibir o trabalho de crianças, mas sim, regulamentá-lo, não especificando uma idade mínima para a contratação de aprendizes; b) a presença de crianças e adolescentes evidenciou e enfatizou a necessidade do Estado de intervir sobre as relações de trabalho, visando estabelecer regras especialmente para garantir condições de saúde no trabalho; $c$ ) as medidas que viriam a ser aplicadas, ao passo que melhorassem as condições e ambientes de trabalho, seriam extensivas aos demais 'outros trabalhadores' (adultos) destas indústrias; d) estabelecia aos empregadores responsabilidades sobre o trabalho, a saúde e a educação de seus aprendizes.

Um dos efeitos dessa lei, contudo, foi 
reduzir gradualmente o emprego de 'aprendizes', mas não o emprego de crianças, que começaram a ser contratadas, então, como 'trabalhadores' que vieram a trabalhar, muitas vezes, em condições ainda piores que as dos aprendizes (GRANT, 1866). Verificou-se que este efeito, ou seja, as estratégias dos proprietários das indústrias para burlar as normas que restringissem o poder de acumulação e lucro do sistema industrial capitalista, foi uma constante durante o século XIX diante da publicação das leis subsequentes que, diante do fracasso inicial de tentar regular a utilização dos aprendizes para proteger a infância, voltaram-se para estabelecer idades mínimas para o emprego. Ainda assim, foram criadas pelos proprietários das indústrias novas formas de burlar a vigilância no controle das idades dos trabalhadores e das jornadas e turnos de trabalho dos trabalhadores menores (JEANS, 1892).

Com exceção da Health and Moral of Apprentices Act, as demais leis trabalhistas inglesas do século XIX analisadas trouxeram a questão da idade mínima para o emprego como um tema central e também especificaram regras específicas para o trabalho de jovens e mulheres. Contudo, a variação no estabelecimento dessas idades mínimas, bem como a ausência de explicação sobre os critérios para a definição dessas idades, sustenta a hipótese de que tais definições estiveram ligadas mais a critérios sociais e econômicos do que às especificidades do desenvolvimento fisiológico e psicológico humano. Observa-se, por exemplo, que, em 1788, estabelecia-se a idade mínima de 8 anos para o emprego na limpeza de chaminés. Em 1840, uma terceira lei especificou o mínimo de 16 anos para aprendizes e de 21 para o trabalho efetivo nessa mesma atividade; mas foi somente em 1864 que foi publicada uma lei, com mais efetividade na aplicação destas regras, definindo a idade mínima de 10 anos para aprendizes e de 16 anos para o trabalho efetivo na limpeza de chaminés. Nas indústrias têxteis, as leis das fábricas (Factory
Acts) estipularam inicialmente a idade mínima de 8 anos para o emprego (em 1919); depois especificaram 9 anos de idade para qualquer trabalho, 13 anos para a jornada de 9 horas e 16 anos para o trabalho noturno (em 1933); voltando, em 1844, a especificar a idade mínima de 8 anos para qualquer trabalho nas indústrias têxteis.

Se por um lado a implementação de regras restritivas ao emprego de crianças em determinadas atividades protegeu as crianças dos prejuízos da inserção precoce em tais atividades, por outro, pode ter ocasionado uma migração do trabalho de crianças para atividades nas quais o poder público tinha pouca ou nenhuma intervenção, causando um gradual processo de invisibilização (e/ ou não reconhecimento) do trabalho infantil. Por exemplo, segundo Humphries (2012), o período em que as principais leis foram publicadas foi marcado por um ingresso mais precoce das crianças em atividades de trabalho de forma geral, ou seja, a época teve simultaneamente uma imposição de idades mínimas em certas atividades e de crianças começando a trabalhar cada vez mais cedo em outras atividades na mesma sociedade. Nardinelli (1981, P. 754) aponta ainda que o declínio na participação de crianças nas indústrias não se deveu necessariamente à publicação das leis, pois seria um processo que já vinha ocorrendo, e que a legislação trabalhista não reduziu a substituição de adultos por crianças, porém acelerou a substituição de crianças por mulheres por ter sido essa "uma forma relativamente fácil dos proprietários obedecerem a lei”. Contudo, é necessário sublinhar que nos relatórios do Parlamento Inglês, sobre o emprego nas indústrias no período de 1835 a 1890, eram considerados: como 'criança', os trabalhadores entre 8 e 12 anos; como 'homens', os trabalhadores do sexo masculino acima dos 18 anos; como 'jovens', os trabalhadores masculinos entre 13 e 17 anos; porém como 'mulheres', eram consideradas todas aquelas acima dos 13 anos (NARDINELLI, 1981). 
A especificação de critérios etários foi de fato confusa nos documentos oficiais do século XIX analisados, por exemplo, sobre $\mathrm{o}$ ingresso na idade adulta. Enquanto nos relatórios das inspeções nas fábricas tem-se que a infância das meninas terminava mais cedo, com a lei Prevention to Cruelty, and Better Protection of, Children Act, de 1889, especificava-se que os meninos deveriam ser protegidos até os 14 anos, já as meninas até os seus 16 anos, denotando - inversamente ao relatório das inspeções industriais - que a infância dos meninos terminava antes.

As delimitações de idade, bem como os sentidos e práticas referentes à infância, estiveram intimamente relacionadas com as reconfigurações do mundo do trabalho (STEARNS, 2006; CORSARO, 2011). Atualmente, a OIT define com a Convenção $\mathrm{n}^{\circ} 182$ que o termo “'criança' designa toda pessoa menor de 18 anos" (OIT, 1999), se este parâmetro fosse o utilizado pelos relatórios das inspeções industriais, por exemplo, o número de trabalhadores menores de idade seria ainda maior do que o já historicamente conhecido, bem como haveria maior restrição à exploração da força de trabalho. Observase que a delimitação e definição dos conceitos (como os conceitos criança, jovem, mulher) foi, em muitas circunstâncias, utilizada de forma estratégica na construção do discurso e dos documentos legais no intuito de proteger as categorias mais vulneráveis à exploração. Todavia, simultaneamente, fizeram-se presentes também outras vozes e interesses, na construção dos discursos, de modo a superar restrições ao avanço do modo de produção industrial e a acumulação de capital advogada como base do progresso econômico. Com as primeiras convenções sobre idade mínimas para o emprego da OIT, publicadas já no século XX, abriam-se exceções para que os Estados nacionais pudessem rever as idades de acordo com suas necessidades econômicas. Conforme especifica o artigo $2^{\circ}$ da Convenção $n^{\circ} 138$ OIT:
Artigo 2 3 . A idade mínima fixada nos termos do parágrafo 1ํ deste Artigo não será inferior à idade de conclusão da escolaridade obrigatória ou, em qualquer hipótese, não inferior a quinze anos. 4. Não obstante o disposto no Parágrafo 3o deste Artigo, o País-membro, cuja economia e condições do ensino não estiverem suficientemente desenvolvidas, poderá, após consulta às organizações de empregadores e de trabaIhadores concernentes, se as houver, definir, inicialmente, uma idade mínima de quatorze anos. Artigo 5 1. O País-membro, cuja economia e condições administrativas não estiverem suficientemente desenvolvidas, poderá, após consulta às organizações de empregadores e de trabalhadores, se as houver, limitar inicialmente o alcance de aplicação desta Convenção. (OIT, 1973).

O próprio site do Parlamento do Reino Unido reconhece ainda hoje que o sucesso econômico da Inglaterra foi devido em grande parte pelo emprego de crianças no primeiro quarto do século XIX pelas indústrias (PARLIAMENT UK, 2014). De forma geral, verificou-se no corpus que as exceções quanto às regras referentes aos limites etários impostos se pautaram em motivos como: 1) a correlação com a obrigatoriedade da instrução primária/elementar; 2) as necessidades das indústrias e do desenvolvimento econômico; 3) a proximidade/responsabilidade da família com o trabalho dos 'menores'.

A despeito de, com a proibição e luta pela erradicação do trabalho infantil, as medidas protetivas terem sido aperfeiçoadas com o passar do tempo, estratégias ideológicas de deslocamentos e inversões observadas na análise do discurso oficial podem favorecer que a solução ao problema da exploração de trabalho infantil seja apresentada sem operar alterações significativas nas bases ideológicas que sustentam a ocorrência e continuidade de tal exploração. Dessa forma, encobre-se o fato que a divisão social e as relações de trabalho no mundo do trabalho ainda sejam calcadas em desigualdades e injustiças e que 
a infância ainda seja uma categoria desconsiderada na produção de conhecimentos e políticas e mais sujeita aos efeitos de diversos problemas sociais, entre os quais encontram-se os agravos à sua saúde ocasionados pela exploração do seu trabalho e as necessidades e demandas sociais que ainda ocasionam a exploração do trabalho de crianças.

Entre tais estratégias observadas a partir da análise da formação ideológica, verificou-se também: a) uma mudança, através de um deslocamento sutil, porém muito significativo que inverte do termo 'emprego' para o termo 'trabalho' enquanto problema social a ser enfrentado e combatido, conotando uma possível representação negativa da categoria trabalho enquanto ato ilícito e tirando de foco, por exemplo, as características das cadeias produtivas que ainda sustentam e se mantêm com a exploração do trabalho de crianças; e b) a continuidade em todo o processo histórico de uma enfática denotação de associação entre pobreza e trabalho.

Em síntese, a análise realizada evidencia o caráter de constructo histórico e social, logo não natural, do próprio conceito 'trabalho infantil', trazendo elementos para a reflexão sobre como, durante processo histórico de sua construção, alguns efeitos de sentido sobre a infância e o trabalho vieram sendo construídos e se materializando nos discursos oficiais, consequentemente, sustentando representações sociais e práticas políticas.

\section{Discussão}

Ao considerar que o discurso, à medida que produz efeitos de sentidos, sustenta e produz práticas políticas e sociais, os resultados e hipóteses produzidos neste trabalho evidenciam o quanto a temática do trabalho infantil é complexa. Evidenciam também que a produção de conhecimentos e ações em saúde ainda deve se debruçar sobre uma série de questões que considerem a dimensão social e histórica da exploração do trabalho de crianças. Nobre (2003, P. 969), sobre o tema do trabalho infantil, verifica que o seu surgimento se dá externamente ao setor saúde e que:

[...] são os organismos internacionais, é o governo federal, é o Fórum Nacional, é o Ministério do Trabalho e Emprego, é o Unicef, é a comissão estadual, que o colocam em cena. Assim, a saúde, o SUS deve assumi-lo e construir sua própria concepção a respeito dele.

Nesse sentido, o presente trabalho buscou trazer alguns apontamentos que expandam a perspectiva crítica acerca do fenômeno da exploração do trabalho infantil e que possam favorecer tanto as estratégias de enfrentamento da exploração objetivando sua erradicação quanto a atenção à saúde de crianças e adolescentes. Estes, a despeito do 'trabalho infantil' ser uma prática proibida, ainda trabalham e/ ou tem suas condições de saúde intimamente relacionadas com o mundo do trabalho.

De acordo com o documento 'Trabalho infantil: diretrizes para a atenção integral à saúde de crianças e adolescentes economicamente ativos', o Sistema Único de Saúde (SUS) tem:

[...] papel de extrema relevância na atenção integral à saúde das crianças e adolescentes trabalhadores, identificando-os, promovendo ações de educação sobre saúde e segurança no trabalho, avaliando a associação entre o trabalho e os problemas de saúde apresentados, realizando ações de vigilância em saúde e atuando de forma articulada com outros setores governamentais e da sociedade na prevenção do trabalho infantil, bem como na erradicação do trabalho infantil perigoso conforme a legislação. Além disso, por estar amplamente distribuído em todo o País e atender a um grande número de indivíduos abaixo dos 18 anos, o SUS é um sistema público de grande capilaridade com potencial para disseminar de forma eficiente esta Política. (BRASIL, 2005, P. 8). 
Entretanto, como se verificou, o processo histórico de proibição do trabalho infantil, por não ter sido acompanhado de transformações contundentes nas bases sociais que sustentam a demanda e a exploração do trabalho de crianças, pode, a despeito de seus evidentes intuitos protetivos, simultaneamente sustentar algumas práticas e representações sociais, dentre as quais: 1) 'invisibilização do trabalho infantil' e 2) 'demarcação do trabalho enquanto atividade inerentemente prejudicial'.

Caracteriza-se aqui o processo de 'invisibilização do trabalho infantil' como um possível efeito adverso da proibição do trabalho infantil que compreende pelo menos quatro aspectos: a) à medida que determinadas atividades foram sendo proibidas, o trabalho de crianças foi migrando para setores econômicos e atividades onde a vigilância e a intervenção do poder público não ocorriam; b) com a categorização do trabalho infantil como crime, crianças e famílias, especialmente aquelas que mais dependem de tais atividades, podem vir a ocultar do poder público a situação de trabalho enquanto tal; c) a enfática associação entre trabalho infantil e pobreza, visível nas campanhas pela erradicação, pode sustentar a impressão de que algumas atividades socialmente valorizadas realizadas por crianças e adolescentes, como desportivas e artísticas, não sejam consideradas trabalho; d) a desconsideração da participação ativa da infância na estrutura e coconstrução da realidade social, por exemplo, por meio do trabalho escolar que, mesmo sendo obrigatório e fundamental à manutenção das economias nacionais, não é considerado como uma forma de trabalho realizado por crianças e adolescentes.

A invisibilidade do trabalho infantil desponta como um dilema para o SUS em sua dupla e paradoxal atribuição, qual seja, de contribuir com a erradicação do trabalho infantil e, simultaneamente, de oferecer atenção integral à saúde de crianças e adolescentes trabalhadores. Marchi (2013), em pesquisa empírica sobre o Programa de
Erradicação do Trabalho Infantil, constata um dos problemas com os quais os serviços de saúde podem se deparar:

A maioria das crianças respondeu, de início, que 'não trabalhava'. Dois fatores podem ter levado a esta negativa: 1) elas não consideravam certas atividades como 'trabalho' (pedir esmolas, trabalho doméstico, catar recicláveis, por ex.); 2) temiam 'assumir' o fato porque isto poderia prejudicar os pais. De forma geral, algumas respostas foram curtas e pareciam dadas em atitude de defesa. (MARCHI, 2013, P. 258).

Ademais, a compreensão da categoria trabalho enquanto determinante das condições de saúde não se mostra problemática tão somente no que tange à atenção à saúde de crianças e adolescentes. Vasconcellos e Machado (2011, P. 37) verificam a existência de uma "blindagem política no sentido de não considerar a centralidade da categoria trabalho nos determinantes sociais dos agravos das populações em geral" que impossibilita a consolidação tanto de um SUS efetivamente sistêmico quanto de uma política nacional de saúde do trabalhador e indicam a necessidade da política "recuperar conceitos". O conceito trabalho infantil e sua consequente proibição vinculam-se muito intimamente com as questões de saúde, muito embora a saúde pública e a saúde do trabalhador tenham pouco ou nenhum protagonismo na produção de conhecimento e intervenção sobre esse fenômeno.

Cabe, por exemplo, sublinhar que o funcionamento ideológico do discurso oficial pode sustentar insuspeitamente uma demarcação do trabalho enquanto atividade inerentemente prejudicial. Se com a lei de 1802, a presença de crianças nas indústrias evidenciou a necessidade de melhores condições de trabalho e impôs regras que, à medida que fossem sendo efetivadas, seriam extensivas aos demais trabalhadores daquelas indústrias, o processo de retirada das crianças de determinadas atividades de trabalho não garantiu melhores condições de vida 
e saúde para as crianças fora das indústrias. Pelo contrário, ainda pode ter servido para tirar a atenção da sociedade e do poder público para a necessidade de intervir na transformação de processos e relações de trabalho a favor da saúde do trabalhador.

Assim sendo, não por acaso, mesmo elencando uma série de atividades que trazem graves riscos à saúde de trabalhadores de qualquer faixa etária, o texto do Decreto 6.841 afirma que

[...] a classificação de atividades, locais e trabalhos prejudiciais à saúde, à segurança e à moral, nos termos da Lista TIP, 'não é extensiva aos trabalhadores maiores de dezoito anos'. (BRASIL, 2008, GRIFO NOSSO).

Se por um lado é evidente que o intuito fundamental seja proteger a infância, por outro, a análise demonstrou a presença de elementos ideológicos que se inseriram e constituíram mesmo os discursos protetivos. Isso evidencia a luta e conflito de interesses aos quais a construção do discurso de erradicação do trabalho infantil também esteve sujeito em sua construção histórica. Portanto, não se trata de invalidar os avanços alcançados na redução da exploração do trabalho de crianças e adolescentes, e que deve prosseguir também com a participação efetiva do SUS, mas de trazer pontos para reflexão que ampliem o debate ao demonstrar a complexidade do tema.

\section{Considerações finais}

Mais do que apresentar conclusões sobre a relação infância/trabalho/saúde, assim como sobre o trabalho infantil e sua proibição, o resultado da referida pesquisa foi demonstrar a complexidade da temática e a necessidade de pesquisas e perspectivas que considerem essa complexidade. Entende-se, aqui, que a generalização ocasionada pelo termo 'trabalho infantil' desconsidere a complexidade e a diversidade da participação da infância na estrutura social, embora tal generalização seja utilizada como um substitutivo mais abrangente para o problema social da exploração do trabalho de crianças e adolescentes. Contudo, coube à análise questionar os efeitos de sentido produzidos pelo discurso e, dessa forma, por em análise a história e a ideologia que demarcam o termo "trabalho infantil' enquanto grave problema social.

Verificou-se que a principal estratégia presente no processo histórico da formação discursiva sobre a imposição de regras trabalhistas, especialmente no que tange ao trabalho de crianças e adolescentes, foi o deslocamento: deslocou-se o enfoque das pautas, reconfiguraram-se os objetos/sujeitos, reformularam-se os predicados, produziram-se novos efeitos de sentido, alterou-se a superfície textual dos enunciados enquanto a base ideológica manteve-se praticamente a mesma. A identificação dessa estratégia ideológica presente no discurso pode ser um possível fator explicativo das dificuldades encontradas na luta contra o problema da exploração do trabalho infantil: reposicionar o problema sem, contanto, enfrentar efetivamente muitas das causas que o sustentam.

\section{Colaboradores}

Valdinei Santos de Aguiar Junior - contribuiu com a definição e a construção da pesquisa, análise e interpretação dos dados e elaboração do texto. Luiz Carlos Fadel de Vasconcellos - contribuiu com orientação da pesquisa, análise dos dados e revisão do texto. Trata-se de um texto elaborado a partir de dissertação de mestrado acadêmico em saúde pública realizado na Escola Nacional de Saúde Pública Sergio Arouca/Fundação Oswaldo Cruz (Ensp/Fiocruz) entre 2013 e 2015. 


\section{Referências}

BRASIL. Decreto nº 6.481, de 12 junho de 2008. Regulamenta os artigos $3^{\circ}$, alínea “d”, e $4^{\circ}$ da Convenção 182 da Organização Internacional do Trabalho (OIT) que trata da proibição das piores formas de trabalho infantil e ação imediata para sua eliminação, aprovada pelo Decreto Legislativo $n^{\circ} 178$, de 14 de dezembro de 1999, e promulgada pelo Decreto $\mathrm{n}^{0} 3.597$, de 12 de setembro de 2000 , e dá outras providências. Diário Oficial [da] União. Brasília, DF, 12 jun. 2008. Disponível em: <http://www.planalto.gov.br/ ccivil_03/_ato2007-2010/2008/decreto/d6481.htm>. Acesso em: 29 mar. 2017.

Ministério da Saúde. Portaria n ${ }^{\circ} 777 / G M$, de 28 de abril de 2004. Dispõe sobre os procedimentos técnicos para a notificação compulsória de agravos à saúde do trabalhador em rede de serviços sentinela específica, no Sistema Único de Saúde - SUS. Diário Oficial [da] União. Brasília, DF, 28 abr. 2004. Disponível em: <http://bvsms.saude.gov.br/bvs/saudelegis/gm/2004/ prt0777_28_04_2004.html>. Acesso em: 29 mar. 2017.

Ministério da Saúde. Portaria n ${ }^{\circ} 1.823$, de 23 de agosto de 2012, Institui a política Nacional de Saúde do Trabalhador e da Trabalhadora. Diário Oficial [da] União. Brasília, DF, 23 mar. 2012. Disponível em: <http://bvsms.saude.gov.br/bvs/saudelegis/gm/2012/ prt1823_23_08_2012.html>. Acesso em: 29 mar. 2017.

Ministério da Saúde. Secretaria de Atenção à Saúde. Trabalho infantil: diretrizes para atenção integral à saúde de crianças e adolescentes economicamente ativos. Brasília, DF: Ministério da Saúde, 2005.

CORSARO, W. A. Sociologia da infância. Porto Alegre: Artmed, 2011.

DEAKIN, S.; WILKINSON, F. The Law of the Labour

Market: Industrialization, Employment and Legal

Evolution. Oxford: Oxford University Press, 2005.

FOUCAULT, M. A ordem do discurso. São Paulo: Loyola, 1996.

GRANT, P. The Ten Hours' Bill: The History of Factory
Legislation, step by step, since its introduction to parliament by the first Sir Robert Peel, in 1802, till it was finally carried by Lord Ashley, in 1850, together with many incidents... London, 1866. Disponível em: <https://books.google.com.br/books?id=y04KAQAAMAA $J \&$ printsec $=$ frontcover\&hl=pt-BR\&source $=$ gbs_ge_summary_r\&cad $=0 \# \mathrm{v}=$ onepage $\& \mathrm{q} \& \mathrm{f}=$ false $>$. Acesso em: 22 maio 2017

HUMPHRIES, J. Childhood and child labour in the British industrial revolution. Economic History Review, 2012. Disponível em: <http://www.parisschoolofeconomics.eu/docs/ydepot/semin/texte1112/JAN2012CHI. pdf >. Acesso em: 22 maio 2017.

JEANS, V. Factory Act Legislation: it's industrial and commercial effects, actual and prospective. Londres: T. Fisher Unwin; Peternoster Square, 1892.

MARCHI, R. C. Trabalho infantil: representações sociais de sua instituição em Blumenau/SC. Educar em Revista, Curitiba, n. 47, p. 249-265, jan./mar. 2013.

NARDINELLI, C. Child Labor and Factory Acts. The Journal of Economic History, Cambridge, v. 40, n. 4, dez. 1980 p. $739-755$.

NOBRE, L. C. C. Trabalho de crianças e adolescentes: desafios da intersetorialidade e o papel do Sistema Único de Saúde. Ciência \&t Saúde Coletiva, Rio de Janeiro, v. 8, n. 4, p. 963-971, 2003.

ORGANIZAÇÃO INTERNACIONAL DO TRABALHO (OIT). Convenção $n^{\circ} 138$ Sobre a idade mínima de admissão ao emprego, 1973. Disponível em: <http://www. tst.jus.br/documents/2237892/0/Conven\%C3\%A7\%C3 $\% A 30+138+$ da + OIT ++ Idade + m\%C3\%ADnima + de + adm iss\%C3\%A3o+ao+emprego>. Acesso em: 30 mar.2017.

Convenção $n^{\circ} 182$ Sobre a proibição das piores formas de trabalho infantil e a ação imediata para a sua eliminação, 1999. Disponível em: <http://www.oitbrasil. org.br/node/518>. Acesso em: 22 maio 2017. 
DECLARAÇÃO DE BRASÍLIA, 2013a. Disponível em: $<$ http://childlabour2013.org/declaracao-de-brasilia-sobre-trabalho-infantil/?lang=pt-br $>$. Acesso em: 20 fev. 2014.

DOCUMENTO BASE PARA III CONFERÊNCIA GLOBAL SOBRE TRABALHO INFANTIL. 2013b. Disponível em: $<$ http://www.oit.org.br/sites/default/files/topic/gender/doc/apresenta\%C3\%A7\%C3\%A3olaisconfglob al_1000.pdf>. Acesso em: 23 fev. 2014.

ORGANIZAÇÃO DAS NAÇÕES UNIDAS (ONU).

Objetivos do Desenvolvimento Sustentável.

TRANSFORMANDO NOSSO MUNDO: a Agenda 2030 para o Desenvolvimento Sustentável. 2015. Disponível em: <https://nacoesunidas.org/wp-content/uploads/2015/10/agenda2030-pt-br.pdf > . Acesso em: 24 ago. 2016.

ORLANDI, E. P. Análise do Discurso: princípios e procedimentos. Campinas: Pontes, 2000.

A linguagem e seu funcionamento: as formas do discurso, São Paulo: Brasiliense, 1983.
PARLIAMENT UK. Reforming society in the 19th century: Early factory legislation. Disponível em: <http:www.parliament.uk/about/living-heritage/ transformingsociety/livinglearning/19thcentury/overview/earlyfactorylegislation/>. Acesso em: 22 jan. 2014.

ROCHA, D. O. S.; DEUSDARÁ, B. Análise de conteúdo e Análise do discurso: o lingüístico e seu entorno. DELTA. Documentação de Estudos em Lingüística Teórica e Aplicada, São Paulo, v. 22, n. 1, p. 29-52, 2006.

STEARNS, P. N. Infância: história mundial. São Paulo: Contexto, 2006.

VASCONCELLOS, L. C. F.; MACHADO, J. M. H. Política Nacional de Saúde do Trabalhador: ampliação do objeto em direção a uma política de Estado. In: MINAYO-GOMEZ, C.; MACHADO, J. M. H.; PENA, P. G. L. (Org.). Saúde do Trabalhador na Sociedade Brasileira Contemporânea. Rio de Janeiro: Fiocruz, 2011.

\footnotetext{
Recebido para publicação em agosto de 2016

Versão final em dezembro de 2016

Conflito de interesses: inexistente

Suporte financeiro: não houve
} 